\title{
Utilidade da Pericardioscopia no Diagnóstico de Derrame Pericárdico
}

\author{
Usefulness of Pericardioscopy in the Diagnosis of Pericardial Effusion
}

Fernando Conrado Abrão, Benoit Jacques Bibas, Paulo Manuel Pêgo-Fernandes, Fabio Biscegli Jatene

Instituto do Coração do Hospital das Clínicas da Faculdade de Medicina da USP, São Paulo, SP - Brasil

O pericárdio pode ser afetado por doenças infecciosas, neoplásicas, inflamatórias e metabólicas. Muitas condições exigem tratamentos específicos, de forma que um diagnóstico preciso é importante. Assim, a biópsia do pericárdio tem um papel importante na avaliação dos derrames pericárdicos. A pericardioscopia oferece a vantagem da tradicional abordagem subxifóide ao permitir acesso a partes do pericárdio que não poderiam ser alcançadas através de palpação digital, bem como visibilização direta através da janela subxifóide ou toracoscopia.

Reportamos o caso de um paciente com grande derrame pericárdico e massa mediastinal não-diagnosticada, em quem a pericardioscopia videoassistida foi fundamental no diagnóstico e tratamento da doença.
The pericardium can be affected by infectious, neoplastic, inflammatory and metabolic diseases. Many conditions require specific treatment and, consequently, an accurate diagnosis is important. Therefore, the pericardial biopsy has an important role in the evaluation of pericardial effusions. The pericardioscopy offers the advantage of the traditional subxiphoid approach, as it allows access to parts of the pericardium that would not be reached by digital palpation, as well as direct visualization through the subxiphoid window or thoracoscopy.

We report the case of a patient with a large pericardial effusion and an undiagnosed mediastinal mass, in which videoassisted pericardioscopy was fundamental in the diagnosis and treatment of the disease.

\section{Introdução}

O pericárdio pode ser afetado por virtualmente qualquer tipo de doença ${ }^{1}$. Algumas dessas condições exigem terapias específicas, e, consequentemente, um diagnóstico etiológico preciso é algumas vezes imperativo. A investigação clínica e os métodos atuais de avaliação por imagem tem tornado o diagnóstico de derrame pericárdico e tamponamento uma prática rotineira. Entretanto, o mesmo não ocorreu em relação à determinação de sua etiologia ${ }^{2}$. Dessa forma, a biópsia pericárdica tem um papel importante na avaliação de derrames pericárdicos de origem indeterminada.

A técnica ideal de biópsia operativa deve confirmar a etiologia do derrame, ser terapêutica e minimamente invasiva. A pericardioscopia videoassistida é um procedimento seguro, permite a inspeção completa da superfície pericárdica e a seleção do local da biópsia, dessa forma aumentando a precisão diagnóstica.

\section{Palavras-chave}

Pericárdio, derrame pericárdico/diagnóstico, biopsia.

Correspondência: Fernando Conrado Abrão •

Rua Souza Ramos, 144 apt. 11 - Vila Mariana - 04120-080 - São Paulo, SP - Brasil E-mail: fernandocabrao@uol.com.br

Artigo recebido em 04/06/09; revisado recebido em 16/06/09; aceito em 21/09/09.

\section{Relato do Caso}

Um jovem de 18 anos foi avaliado devido à dispnéia progressiva com duração de três semanas. Ele negou a ocorrência de febre, suores noturnos e perda de peso. O exame físico não revelou adenopatia periférica. O paciente estava taquicárdico e a pressão arterial sistêmica era de 100 × $70 \mathrm{mmHg}$. Ele apresentava pressão de pulso estreita acompanhada de pulso paradoxal, bulhas cardíacas distantes e pressão venosa central elevada. Os sons pulmonares estavam normais. A tomografia computadorizada (TC) revelou uma grande massa mediastinal, associada a um grande derrame pericárdico (Figuras 1A e 1B). O ecocardiograma revelou sinais de compressão atrial e ventricular direita. Foi decidido realizar uma pericardioscopia videoassistida a fim de drenar, inspecionar e biopsiar o pericárdio.

O paciente foi operado através de uma pequena incisão subxifoide na linha média, sob anestesia geral. A técnica operatória já foi descrita anteriormente ${ }^{3}$.

A pericardiocentese permitiu a remoção de $1.500 \mathrm{ml}$ de fluido pericárdico. A pericardioscopia videoassistida foi realizada e mostrou invasão neoplásica macroscópica na porção superior do pericárdio (Figura 2). As biópsias guiadas foram realizadas e enviadas para análise histológica. Uma ampla ressecção pericárdica anterior também foi realizada, com o objetivo de reduzir a recorrência. O espaço pericárdico foi drenado através de um tubo de toracostomia. O paciente apresentou uma recuperação livre de intercorrências e o diagnóstico final foi linfoma de Hodgkin. 


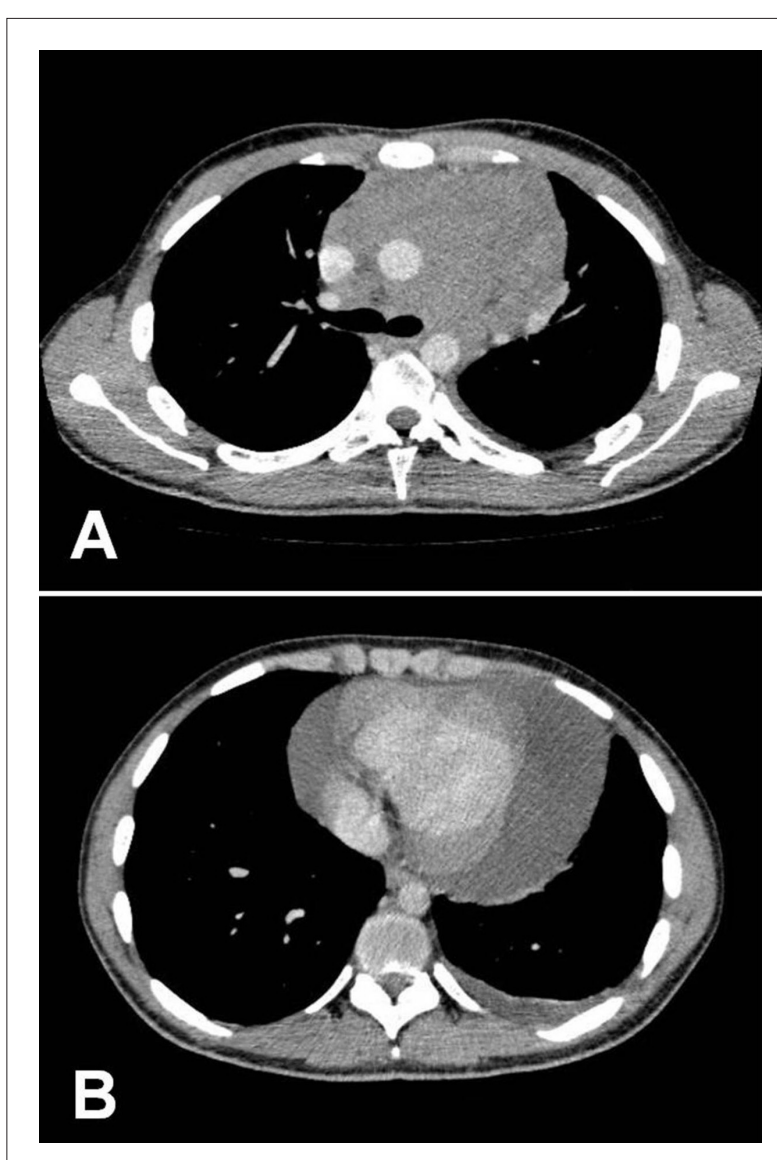

Fig. 1A e 1B - Tomografia computadorizada do tórax, mostrando: (A): Grande massa mediastinal anterior medindo $13 \times 10 \mathrm{~cm}, \mathrm{e}(\mathrm{B})$ : Grande derrame pericárdico.

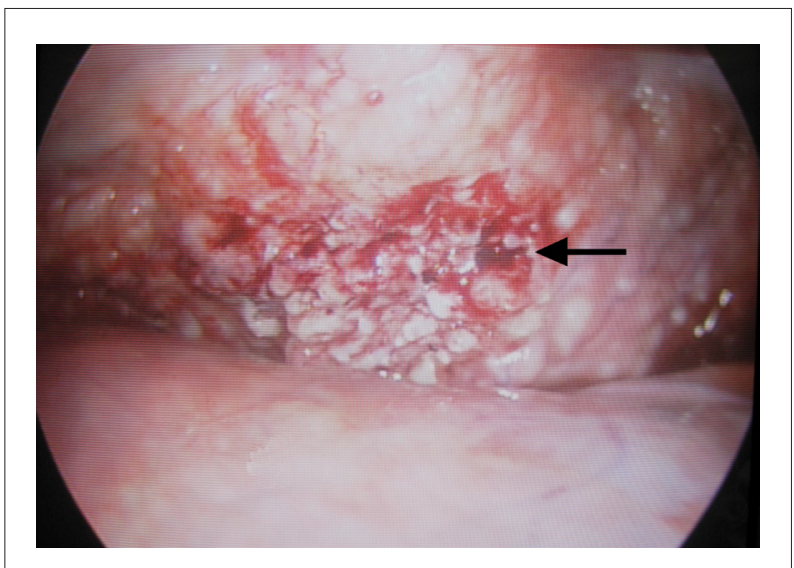

Fig. 2 - Imagem pericardioscópica vídeoassistida, mostrando extensa infiltração neoplástica da parte posterior do pericárdio. A seta indica o local selecionado da biópsia.

\section{Discussão}

Os métodos diagnósticos invasivos são necessários a fim de identificar as etiologias da pericardite. A biópsia pericárdica é o procedimento mais comumente realizado ${ }^{4}$.
A rota de acesso para a biópsia pericárdica pode ser por via transtorácica, esternotomia mediana ou subxifoide ${ }^{2}$. O exame do derrame é difícil, pois há limitações citológicas e microbiológicas na análise do fluido pericárdico ${ }^{3,4}$. Em relação à biópsia pericárdica, a maior limitação é a dificuldade de obter tecido adequado para a análise. A tradicional abordagem subxifoide permite uma exposição limitada do pericárdio, resultando em um baixo índice de diagnóstico etiológico e taxas de recorrência de derrame pericárdico de até $20 \%{ }^{5}$. Com o desenvolvimento do equipamento endoscópico, foi possível introduzir novas técnicas, tais como a pericardiocospia videoassistida $^{2,3}$ e a janela pericárdica toracoscópica ${ }^{6,7}$.

A janela pericárdica toracoscópica é uma técnica efetiva para drenagem pericárdica ${ }^{6,7}$. Tem a vantagem de permitir a realização simultânea de procedimentos adicionais, tais como a biópsia de massas mediastinais ou o tratamento de um derrame pleural ${ }^{6,7}$. Entretanto, a necessidade de ventilação pulmonar única, anestesia geral e a necessidade de posicionamento lateral (que impede o fácil acesso ao pericárdio) podem limitar o papel do procedimento em pacientes hemodinamicamente instáveis ${ }^{8}$. O'Brien e cols. ${ }^{8}$ compararam 15 janelas pericárdicas toracoscópicas com 71 abordagens subxifoides. A morbidade geral dos procedimentos foi baixa, mas foi mais alta no grupo da janela pericárdica e estava relacionada em sua maioria à complicações associadas com o acesso do espaço pleural (particularmente pneumotórax). A maior morbidade parece refletir a maior complexidade do procedimento. Recorrência foi observada em 1 paciente após a toracoscopia (8\%) e em 5 pacientes após a abordagem subxifoide $(10 \%)$ e o tempo de anestesia foi significantemente mais longo na toracoscopia.

A pericardioscopia videoassistida oferece as vantagens da abordagem subxifoide tradicional: 1) o paciente permanece na posição supina e o acesso está prontamente disponível para pericardiocentese, se houver instabilidade após a indução; 2) pode ser realizada sob anestesia local; 3) não necessita de ventilação pulmonar única; 4) não penetra o espaço pleural e 5) a incisão abdominal não confere risco de neuralgia prolongada que pode ocorrer após a toracotomia ${ }^{2,3,8}$. Além disso, ela permite a visibilização direta da superfície pericárdica e biópsias guiadas de áreas suspeitas ou depósitos intrapericárdicos. Dessa forma, ela permite o acesso a partes do pericárdio que não poderiam ser alcançadas através de palpação digital, visibilização direta através da janela subxifoide ou toracoscopia ${ }^{3}$.

Neste caso, o objetivo do procedimento cirúrgico era a resolução do risco de tamponamento cardíaco e fornecer um diagnóstico etiológico. O ecocardiograma mostrou sinais de compressão atrial e ventricular direita, e por essa razão, decidimos manter o paciente na posição supina e a abordagem cirúrgica foi feita através da pericardioscopia videoassistida. Outra abordagem seria a tradicional biópsia subxifoide; entretanto, o tumor não seria alcançado por que estava na parte superior do pericárdio, na emergência da aorta.

Porte e cols. ${ }^{9}$ avaliaram 114 pacientes com derrame pericárdico e histórico de câncer. Em 22.7\%, a pericardioscopia melhorou os resultados da citologia do fluido pericárdico e a biópsia pericárdica cirúrgica. As sensibilidades dos estudos citológicos do fluido pericárdico, exames patológicos da 


\section{Relato de Caso}

biópsia pericárdica e biópsia pericárdica pericardioscópica foram de $75 \%$, 65\% e $97 \%$ respectivamente. A mortalidade perioperatória foi de $3,5 \%$, e a morbidade pós-operatória foi de $6,1 \%$.

Analisamos 91 pacientes com derrames pericárdicos de origem indeterminada que foram submetidos à pericardioscopia videoassistida em um período de 9 anos $^{3}$. O diagnóstico foi estabelecido da seguinte forma: inflamação não-específica em 50 (54,94\%) casos, doenças neoplásicas em 22 (24,17\%) casos, tuberculose em 11(12,08\%) casos, processo inflamatório bacteriano em 3 (3,29\%) casos, quilopericárdio em 2 (2,19\%) casos, infecções fúngicas em 2 (2,19\%) casos e infecção viral em 1 (1,09\%) caso. Biópsias guiadas videoassistidas do pericárdio estabeleceram o diagnóstico em 36,26\% dos casos; o diagnóstico através da análise do fluido foi obtido em $13.18 \%$ dos casos e uma associação de ambos os métodos garantiram 45,05\% de diagnósticos definitivos no estudo. A morbidade geral foi de $4,3 \%$ e as complicações mais comuns foram arritmias devido à manipulação intra-operatória. Houve 1 óbito $(1,09 \%)$ no período perioperatório devido a tamponamento cardíaco durante a indução da anestesia, apesar da drenagem imediata do derrame.

\section{Referências}

1. Hoit BD. Pericardial disease and pericardial tamponade. Crit Care Med. 2007; 35 (8 Suppl): S355-64

2. Pêgo-Fernandes PM, Fernandes F, lanni BM, Rohr SS, Bernardelli IM, Jatene FB, et al. Video-assisted pericardioscopy: how to improve diagnostic efficacy in pericardial effusions. Arq Bras Cardiol. 2001; 77 (5): 399-406.

3. Pêgo-Fernandes PM, Mariani AW, Fernandes F, lanni BM, Stolf NG, Jatene FB. The role of videopericardioscopy in evaluating indeterminate pericardial effusions. Heart Surg Forum. 2008; 11 (1): E62-5.

4. Fernandes F, lanni BM, Arteaga E, Benvenutti L, Mady C. Value of pericardial biopsy in the etiologic diagnosis of pericarditis. Arq Bras Cardiol. 1998; 70 (6): 393-5.

5. Naunheim KS, Kesler KA, Fiore AC, Turrentine M, Hammell LM, Brown JW, et al. Pericardial drainage: subxiphoid vs transthoracic approach. Eur J Cardiothorac Surg. 1991; 5 (2): 99-104.

\section{Conclusão}

A pericardiocospia videoassistida é um método seguro e eficiente de obter um diagnóstico definitivo e resultados terapêuticos satisfatórios em casos de derrame pericárdico de origem indeterminada. A excelente visualização da superfície pericárdica permite a biópsia guiada de áreas suspeitas. Também permite acesso a regiões do pericárdio que não seriam alcançadas através do uso de outras técnicas de biópsia disponíveis.

\section{Potencial Conflito de Interesses}

Declaro não haver conflito de interesses pertinentes.

\section{Fontes de Financiamento}

O presente estudo não teve fontes de financiamento externas.

\section{Vinculação Acadêmica}

Não há vinculação deste estudo a programas de pósgraduação.

6. Georghiou GP, Stamler A, Sharoni E, Fichman-Horn S, Berman M, Vidne BA, et al. Video-assisted thoracoscopic pericardial window for diagnosis and management of pericardial effusions. Ann Thorac Surg. 2005; 80 (2): 607-10.

7. Neragi-Miandoab S, Linden PA, Ducko CT, Bueno R, Richards WG, Sugarbaker DJ, et al. VATS pericardiotomy for patients with known malignancy and pericardial effusion: survival and prognosis of positive cytology and metastatic involvement of the pericardium: a case control study. Int J Surg. 2008; 6 (2): 110-4.

8. O'Brien PK, Kucharczuk JC, Marshall MB, Friedberg JS, Chen Z, Kaiser LR, et al. Comparative study of subxiphoid versus video-thoracoscopic pericardial "window". Ann Thorac Surg. 2005; 80 (6): 2013-9.

9. Porte HL, Janecki-Delebecq TJ, Finzi L, Métois DG, Millaire A, Wurtz AJ. Pericardoscopy for primary management of pericardial effusion in cancer patients. Eur J Cardiothorac Surg. 1999; 16 (3): 287-91. 